\title{
A survey of recommendations given to patients going home after bone marrow transplant
}

\author{
L Brandt, V Broadbent
}

\begin{abstract}
A postal questionnaire was sent to $11 \mathrm{UK}$ Children's Cancer Study Group bone marrow transplant centres asking them for details of their instructions to patients on discharge after either allogeneic or auto transplant; nine centres responded. There was no recommendation on which they all agreed. Though all centres gave prophylactic septrin, the times of starting and stopping treatment varied considerably. Three centres recommended lifelong penicillin after total body irradiation, one treated for two years and five gave no such prophylaxis. Four of nine centres gave routine acyclovir for herpes simplex prophylaxis. Most centres suggested prophylaxis against varicella after contact exposure for one year. However, three gave zoster immune globulin alone, one gave this together with acyclovir, and five gave acyclovir alone. No two centres recommended the same dose of acyclovir. Vaccinations were allowed from 6-18 months after transplant. One centre required documentation of recovery of immune function first. Four centres recommended a child stay off school for six months; others had 'common sense' approaches. Only one centre did not allow family holidays for the first six months but many imposed restrictions on these holidays. Dietary restrictions varied greatly between centres.
\end{abstract}

It is concluded that there is a need for unified and scientifically justified guidelines after transplant for paediatric bone marrow transplant patients.

(Arch Dis Child 1994; 71: 529-531)

As a paediatric oncology unit without the facility to perform allogeneic bone marrow transplant (BMT) at present, we refer patients to other centres for this procedure. They return, each with a different set of follow up instructions. This is confusing for parents who talk among themselves, as well as for medical and nursing staff. In order to highlight this problem nationally, we audited specific recommendations given by 11 UK Children's Cancer Study Group centres to patients after transplant. A postal questionnaire asking eight specific questions was sent to each centre and we present the results of the replies.

Results

Nine of the 11 centres replied.

\section{PROPHYLACTIC SEPTRIN}

Centres were asked about their use of prophylactic septrin. The decision on when to start prophylaxis depended on 'count recovery' in five centres but was at a given time period in four. There was variation in the definition of count recovery, with one centre requiring a neutrophil count of $>0.5 \times 10^{9} / 1$, and others a neutrophil count of $>1.0 \times 10^{9} / 1$. There was no agreement between those centres that specified times of starting septrin; one started on day 1 , one on day 2 , and two on day 28 .

The dose of septrin recommended was 480 $\mathrm{mg} / \mathrm{m}^{2}$ three times a week in eight of nine centres, and daily in the other. One centre decreased the dose to weekly if the marrow was slow to reconstitute or if the child was taking azathioprine. Septrin was stopped at three months after autograft by five centres, the other four continuing for six months. Seven centres continued septrin for six months after allograft and two centres stopped it at three months.

\section{PROPHYLACTIC PENICILLIN}

Lifelong prophylactic penicillin for presumed hyposplenism after total body irradiation was recommended by three centres. In one of these, penicillin was stopped if there was a documented response to pneumococcal vaccine at six months after autologous BMT or at 12 months after allogenic BMT. One centre gave penicillin for an arbitrary two years. Five centres did not give routine penicillin, but two of these would prophylactically treat a child who was given a splenic boost or who had chronic graft versus host disease.

\section{ACYCLOVIR PROPHYLAXIS}

Routine prophylaxis against herpes simplex after transplant was recommended by four of nine centres. The length of this treatment varied from 42 days to six months.

The time period for which patients were considered to be at risk from varicella varied from 6-18 months. The recommended prophylactic treatment for exposed children varied greatly. Four centres gave acyclovir alone, two gave acyclovir and zoster immune globulin, and three gave zoster immune globulin alone. There was no consensus on the dose of acyclovir prescribed.

\section{VACCINATIONS}

One centre allowed killed vaccine any time after transplant and one at six months after autograft but 12 months after allograft. Four 
centres waited for 12 months and three for 18 months regardless of type of transplant. There was even more variation in the time at which live vaccines were allowed.

\section{RETURN TO SCHOOL}

The time children were kept away from school varied widely. Some centres allowed children back when they were fit, some made specific stipulations such as being off cyclosporin or having a neutrophil count greater than $1.0 \times 10^{9} / 1$ and others stipulated a three or six month absence.

\section{HOLIDAYS}

Centres were asked if they would allow families to take holidays within the first six months after transplant. Most centres did allow holidays, however, there were generally restrictions imposed such as 'clean' countries or UK only. Avoidance of crowded places was recommended by one centre and two centres suggested that patients should avoid swimming for six months.

\section{DIETARY ADVICE}

Centres were asked to comment on the dietary advice and restrictions they gave when a child returned home after transplant. Most recommended a 'clean' diet but the duration of the restriction varied. Two centres imposed no restrictions and one banned live yoghurt and 'take aways' only.

\section{Discussion}

During BMT the patient is isolated in a protected environment ${ }^{1}$ and is closely monitored. When the patient is a child, parents are encouraged to be actively involved in care and are taught the importance and significance of these protective measures. Once the child is discharged from this protected environment he/she is no longer closely monitored and parents assume responsibility for their child's welfare. This is seen by most parents as an awesome responsibility and the instructions that they are given are likely to be strictly adhered to. These instructions, therefore, need to have a rational and scientific basis.

The results of our survey show that there is a wide discrepancy between UK centres in recommendations given to paediatric patients after BMT. Asked to comment on the basis for their recommendations, most centres said that they were based on personal practice which had evolved over time and that appeared to achieve satisfactory results rather than being based on precise research data.

The risk of bacterial, viral, and fungal infections is greatest in the immediate period after transplant ${ }^{2}$ and declines with the return of granulocytes, recovery of an intact gastrointestinal tract mucosa, and re-establishment of immunocompetence. By the time the child is sent home, the first two of these criteria are usually achieved. Recovery of immunocompetence is much harder to define and may be affected by such phenomena as $T$ cell depletion of allogenic marrow and presence or treatment of graft versus host disease. The difficulty in documenting return of immune competence is the main barrier to a rational approach to 'home going' prophylaxis.

There is no doubt that certain measures such as the use of prophylactic septrin to prevent Pneumocystis carinii pneumonia ${ }^{3}$ and acyclovir used after contact and as treatment for overt varicella, ${ }^{4}$ as well as for prevention of herpes zoster, ${ }^{5}$ have dramatically reduced infectious mortality after transplant but length of prophylaxis remains arbitrary. Evidence for the need for prolonged penicillin prophylaxis after total body irradiation is difficult to find and the value of preirradiation polyvalent pneumococcal vaccine in these circumstances is not proved. ${ }^{6}$

Whether the immune system of a successful bone marrow transplant recipient should be regarded as virgin, thus requiring complete revaccination, or regarded as having taken on the profile of the donor remains controversial. ${ }^{7}$ Inactivated and single constituent vaccines can be given once host lymphocytes are able to produce functional antibodies. The timing of this event awaits more substantiation.

Although sterile diets and gut decontamination were a feature of the early days of transplantation, ${ }^{8}$ they are cumbersome and have been abandoned for a clean diet in most centres. This involves food items known to have a low bacterial content ${ }^{9}$ and a 'cooked food only' policy. Most children do not want to eat during the period of mucositis after high dose chemotherapy/total body irradiation but by the time they are discharged from hospital usually have an intact gastrointestinal mucosa and return of appetite. There is no evidence available to show that restriction of diet at this stage serves any useful purpose.

Respiratory viruses such as adenovirus and respiratory syncytial virus are uncommon in the late phase after BMT and may be the result of reactivation rather than person to person transmission. ${ }^{10}$ There is no evidence to date that early return to school is associated with an increased risk of these infections.

Instructions given to parents of a child who has returned home after BMT are taken seriously. They have a great impact on family life, particularly when they involve issues such as when a child can return to school, eat a normal diet, or go on an unrestricted holiday, and need to be justified after careful consideration supported by clinical research. At present these recommendations are based on a commonsense approach rather than on precise research data. As more BMTs are performed there will be a larger population with which to validate these issues. This is now being addressed by the BMT group of the UK Children's Cancer Study Group.

We should like to thank those UK Children's Cancer Study Group BMT centres who kindly completed our questionnaire. 
1 Mooney BR, Reeves SA, Larson E. Infection control and bone marrow transplantation. Am $\mathcal{f}$ Infect Control 1993; 21: 131-8.

2 Zaia JA. Viral infections associated with bone marrow transplantation. Hematol Oncol Clin North Am 1990; 4: 603-23.

3 Hughes WT, Rivera GK, Schell MJ, Thornton D, Lott L. Successful intermittent chemoprophylaxis for Pneumocystis carinii pneumonitis. $N$ Engl $\mathcal{f}$ Med 1987; 316: 1627-31.

4 Feldman S, Lott L. Varicella in children with cancer: impact of antiviral therapy and prophylaxis. Pediatrics 1987; 80: 465-72.

5 Perren TJ, Powles RL, Easton D, Stolle K, Selby PJ Prevention of Herpes zoster in patients by long term oral Prevention of Herpes zoster in patients by long term oral acyclovir after allogeneic bone marrow

6 Giebink GS, Lee CT, Schiffman G. Decline of serum antibody in splenectomised children after vaccination with pneumococcal capsular polysaccharides. $\mathcal{f}$ Pediatr 1984 ; 105: 576-82.

7 Lee N, Kobayashi RH. Immunisations in the immunocompromised host. In: Patrick CC, ed. Infections in immunocompromised infants and children. New York: Churchill Livingstone, 1992: 745

8 Pizzo PA, Levine AS. The utility of protected environment regimes for the compromised host: a critical assessment. Progress in Hematology 1977; 10: 311-32.

9 Pizzo PA, Purvis DS, Waters C. Microbial evaluation of food items. f Am Diet Assoc 1982; 81: 272-9.

10 Shields AF, Hackman RC, Fife KH, Corey L, Meyers J. Adenovirus infections in patients undergoing bone marrow transplantation. N Engl f Med 1985; 312: 529-33.

\section{Commentary}

This paper was first presented at a scientific meeting of the UK Children's Cancer Study Group. It highlighted the apparent wide variation in post bone marrow transplant practice and merited a referral to the UK Paediatric Bone Marrow Transplant Group for an attempt at standardisation and a unified approach. The group will publish national guidelines on the recommendations of care after bone marrow transplant by the end of 1994 .

A survey of national and international practice has revealed that there are as many opinions as there are transplanting units and it has to be acknowledged that at times there is more art than science to many of our recommendations. The aim is to adopt a commonsense approach having guided the child through the transplant procedure with its potentially lethal complications of graft rejection, graft versus host disease, and infection. At no time, however, should there be any compromise on safety.

The return to normal life as quickly as possible is a high priority with recognition that the family as a whole needs to settle to a less stressful routine. Nevertheless it must be appreciated that the extent of care after transplant is determined by clinical course and any individual transplant unit may have some firm ideas on certain aspects of care. It should be remembered particularly with the growth of unrelated donor bone marrow transplantation in specialised units that the degree of immunosuppression differs and hence the precautions advised after transplant will inevitably vary widely.

It has become clear, therefore, that rigid guidelines are impossible and there will always be variations dictated by disease and clinical course. Wherever possible a unified approach will be adopted to minimise the problem of complex and diverse take home instructions in this vulnerable group of children.

JACQUELINE CORNISH (Chairman, UK CCSG Paediatric Bone Marrow Transplant Group) Directorate of Children's Services, Bristol Royal Hospital for Sick Children, St Michael's Hill, Bristol BS2 8Bf 